\title{
Population Trends \& Obesity Patterns in the Philippines: A Window to the Obesity Epidemic in the Asia-Oceania Region
}

\author{
Augusto D. Litonjua \\ Founding President \\ Philippine Association for the Study of Overweight and Obesity (PASOO)
}

\begin{abstract}
Dr. Lee Kaplan, in his lecture at the recently concluded Postgraduate Course in Endocrinology (Harvard Medical School, Boston, MA, USA) described obesity as a very common and growing problem, with a complex physiology and clinically heterogenous picture, resistant to treatment as well as frustrating to manage. It should be a global health problem priority since it is associated with multiple endocrine and metabolic disturbances.
\end{abstract}

The complications of obesity, as summarized by Kaplan, are metabolic, structural, inflammatory, degenerative, neoplastic, psychological and is associated with 60 medical syndromes and 12 different types of cancer.

What is the problem of obesity in the Philippines, and its determinants?

Adair in 2004, ${ }^{1}$ working in Metro Cebu, saw the prevalence of overweight and obesity increase nearly 6 fold from about 6\% in 1983 to 1984 to 35\% in 1998 to 1999. Weight gain was positively associated with urban residence, improved socioeconomic status, fewer pregnancies and months of lactation, and more "away from home" work hours. The risk of hypertension was independently elevated by high waist-hip ratio and overweight/obesity.

Sy et al, ${ }^{2}$ took up the prevalence studies from 1993 to 2008. The rise continued - about $3.4 \%$ of their studied population being obese (BMI greater than $30 \mathrm{~kg} / \mathrm{m}^{2}$ ) in 1993 and climbing to $5.2 \%$ in 2008 . On the other hand, the overweight subjects in their study population rose from $15.2 \%$ to $21.4 \%$ in the same period.

In addition to the factors outlined by Adair, some of the dietary characteristics - especially fat - went up from $11.6 \%$ in 1984 to $17 \%$ in 1999 . We also noted the geometric increase of the Philippines' Number 1 fastfood eatery Jollibee - from 10 stores in 1981 to 600 stores in 2007. These outlets serve calorie dense foods, coming mostly from fats.

The prevalence of the metabolic syndrome - some relationship to the obesity problem?

The literature is rife with reports of the parallel rise of the metabolic syndrome with obesity. This is understandable, since obesity - especially visceral obesity - is part of the syndrome. In the International Diabetes Federation definition, visceral obesity is a sine qua non for the diagnosis of metabolic syndrome.

In the NNHeS survey of 2003-2004, ${ }^{3}$ the prevalence of the syndrome was $18.6 \%$ of the surveyed population $(17.5 \%$ for males and $19.7 \%$ for females). This compares with the prevalences in some Asian countries.

Are the component risks for the metabolic syndrome the same for all populations?

The component of the metabolic syndrome which occurs the highest is low HDL cholesterol, occurring in $60.2 \%$ of men and $80.9 \%$ of women. This contrasts with abdominal obesity which is present in $17.7 \%$ in men and $35.1 \%$ in women. Hypertension is present in $33 \%$ of the surveyed population, hypertriglyceridemia in $20.6 \%$ and FPG greater than $100 \mathrm{mg} \%$, 7.1\%.Non-alcoholic fatty liver disease (NAFLD) is increasing in prevalence in the Philippines; associated with obesity ( $60 \%$ ) and diabetes (69\%) (Table 1). ${ }^{4}$

If there are no studies as yet, it may be worthwhile to compare the components of the metabolic syndrome of

Table 1. Comparison between studies of the characteristic features of NAFLD* patients ${ }^{4}$

\begin{tabular}{|c|c|c|c|c|c|c|}
\hline Author of Study & No. of Patients & Age (yrs) & $\%$ Female & $\%$ Diabetes & $\%$ Obesity & $\%$ Hepatomegaly \\
\hline Ludwig (1988) & 20 & 54 & 65 & 50 & 90 & 67 \\
\hline Diehl (1988) & 39 & 52 & 81 & 55 & 71 & 20 \\
\hline Lee (1989) & 49 & 53 & 78 & 51 & 69 & - \\
\hline Powell (1990) & 42 & 49 & 83 & 36 & 95 & 81 \\
\hline Bacon (1994) & 33 & 47 & 42 & 21 & 39 & 21 \\
\hline Matteoni (1999) & 132 & 53 & 53 & 33 & 70 & 92 \\
\hline Khurram (2003) & 50 & 47 & 54 & 44 & 66 & 76 \\
\hline De Lusong(2008) & 134 & 42 & 71 & 69 & 60 & 56 \\
\hline
\end{tabular}

ISSN 0857-1074

Copyright $@ 2011$ by the JAFES

Received October 18, 2011. Accepted October 18, 2011.

Plenary lecture delivered on August 31, 2011 at the 6th Asia-Oceania Conference on Obesity, Sofitel, Philippines.
Corresponding author: Augusto D. Litonjua, MD

Founding President

Philippine Association for the Study of Overweight and Obesity

Rm. 362 Makati Medical Center, \#2 Amorsolo St.,

Makati City, Philippines

Tel. No.:+63 810-2897 
Asian countries with those of Western countries. In one study comparing the incidence of dyslipidemia (cholesterol levels above $240 \mathrm{mg} \%$ ), the US data in 2002 showed $17.1 \%$ of their population with hypercholesterolemia present in only $5.4 \%$ of the population.

There have been shown in the past studies differential phenotypes for type 2 diabetes mellitus in Asia countries.

There is need for more studies involving the differential genotypes for type 2 diabetes mellitus - there have been several in the past, and more are needed to come up with a clearer understanding of the differences of the manifestations of the disease in different populations.

\section{References}

1. Adair, LS. Dramatic rise in overweight and obesity in adult Filipino women and risk of hypertension. Obes Res. 2004;12:1335-1341.

2. Dans AL, Morales DD, Velandria F, Abola TB, Roxas A, Punzalan FE, Sy RA, Paz-Pacheco E, Amarillo L and Villaruz MV for the NNHeS 2003 Group. National Nutrition and Health Survey (NNHeS): Atherosclerosis-related Diseases and Risk Factors. Philippine Journal Internal Medicine 43:102-115, May-June 2005.

3. Sy, R, et al for the National Nutrition and Health Survey 2008 working group. Manuscript in preparation. For publication.

4. De Lusong MAA, Labio E, Daez L, Gloria V, Non -alcoholic fatty liver disease in the Philippines: Comparable with other nations? World J Gastroenterol. 2008; 14(6): 913-917 Available from: URL: http://www.wjgnet.com/1007-9327/14/913.asp DOI: http://dx.doi.org/10.3748/wjg.14.913.

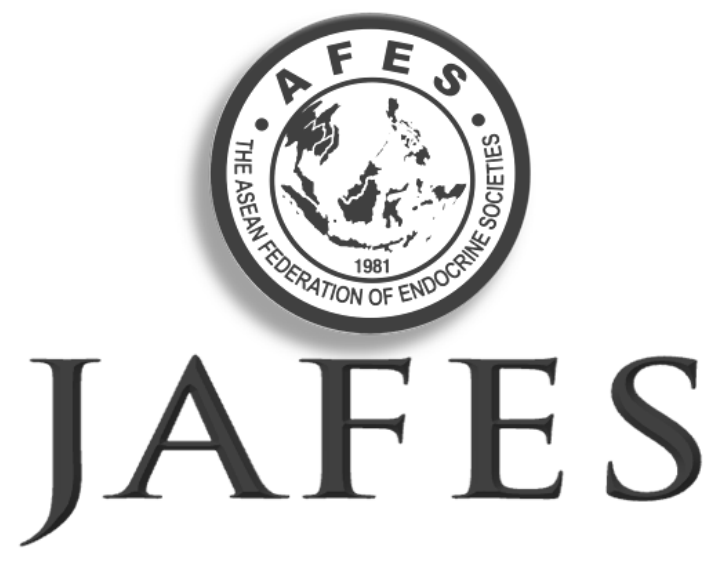

\section{Clinical controversies and disease updates are also welcome. Instructions to Authors available at www.ASEAN-endocrinejournal.org.}

